Working Paper 03-51

Economics Series 20

December 2003
Departamento de Economía Universidad Carlos III de Madrid

Calle Madrid, 126

28903 Getafe (Spain)

Fax (34) 916249875

\title{
CAN JOB COMPETITION PREVENT HOLD-UPS? *
}

\author{
Marcel Jansen
}

\begin{abstract}
We consider an economy in which firms need to invest in capital before they can advertise a job, while applicants may have to compete for jobs. Our aim to investigate how this competition affects the investment decisions of firms. Our first finding shows that the economy always generates the right number of jobs. However, with random search firms under-invest in capital. In contrast, if workers can direct their search towards firms with different capital levels, the equilibrium is efficient. This result contrasts sharply with the predictions of models with ex post wage bargaining that never yield an efficien allocation. Moreover, our results extend the efficiency of auction mechanisms to an environment with non-contractible investments.
\end{abstract}

Keywords: hold-up, search, efficiency and auctions.

JEL Classification: C78, D44, D83.

M. Jansen, Departamento de Economía, Universidad Carlos III de Madrid. E.mail: jansen@eco.uc3m.es. Phone: (34) 916245740

\footnotetext{
* This paper is based on Chapter 1 of my PhD thesis at the EUI in Florence. I am grateful to Ramon Marimon for supervision, and I would like to thank Giuseppe Bertola, John Kennes, Klaus Kultti, Claudio Michellacci, Dale Mortensen and Christopher Pissarides and seminar audiences at the SED 1999 (Alghero), EUI, University of Helsinki and Universidad Carlos III de Madrid for helpful comments.
} 


\section{Introduction}

Under what conditions do firms offer an efficient distribution of jobs? In most cases the answer depends on the type of labour market under consideration. Here we concentrate on a labour market with search frictions. Furthermore, we assume that firms need to invest in capital before they can enter the labour market to look for a worker. A firm's investment is therefore not contractible and surplus sharing may allow workers to appropriate a share of the returns on capital.

There is a sizeable literature that studies this type of hold-up problem ${ }^{1}$ within the realm of a standard matching model, assuming pairwise meetings between firms and workers and bilateral wage negotiations. In that environment the job distribution is never efficient (Davis, 2001). Either workers have some bargaining power and wages increase with capital, creating a holdup problem, or all bargaining power is vested in firms, leading to very low wages and excessive entry of firms. Moreover, similar arguments have been advanced for investments in education (Laing, Palivos and Ping Wang, 1995, and Moen, 1998), in general training (Acemoglu, 1997) and for complementary investments in education and capital (Acemoglu, 1996, and Masters, 1998).

The innovation of this study is that we allow for competition among potential trading partners. Despite the market frictions, firms may attract

\footnotetext{
${ }^{1}$ Williamson (1975) and Groult (1984) show that hold-up problems arise due to a lack of complete contingent contracts; with complete contracts all those who benefit from an investment could be forced to pay their share of the cost. The hold-up literature also proposed a number of solutions: parties can reallocate property rights (Williamson (1975), Hart and Moore (1990)), impose breach penalties (MacLeod and Malcomson (1993)), or enter into long-term relationships (Williamson (1975)). However, all these solutions require that agents can arrange their relationships before they make the investment. This is excluded by our assumption that investments are made before the firms meet workers.
} 
more than one applicant for the same job. The threat that the firm may hire a different applicant therefore tends to limit the bargaining power of workers vis-á-vis firms. To capture this natural loss of bargaining power, we assume that firms auction their jobs to applicants. In accordance with the existing literature, wages are therefore determined after the investments are made. But applicants may have to compete with other workers to obtain the job they applied for.

Our results show that this mechanism induces an efficient resource allocation provided that workers can direct their search to different types of firms.

The analysis builds on the recent literature on search and auctions (e.g. Kultti, 1998, Shimer, 1999 or Julien, Kennes and King, 2000). This literature established that auction mechanisms can induce efficiency in the standard search environment. The characteristic of the efficient mechanisms is that sellers use a reservation bid at the level of their endogenous outside option value.

In order to focus on the investment margin, we initially restrict our attention to this class of efficient mechanisms. The particular rule that we consider is a sealed bid second prize auction. In that case, the outcome of the wage negotiations is reminiscent of Bertrand competition: either the firm has two or more applicants who both receive their reservation wage (irrespective of whether they are hired or not), or the firm has a single applicant who appropriates the entire surplus of the match. We show that these payments reflect the actual productivity of applicants. For a given investment level, firms therefore have the right incentives to create jobs. Nonetheless, the surplus of a job may accrue to the worker and this creates a scope for hold-ups.

This scope for hold-ups is formalized by our first result. It shows that the equilibrium is never efficient if workers apply for randomly selected jobs. The problem with a random assignment of workers to jobs is that all firms face 
the same probability to attract a single applicant. Since the surplus of a job increases with the capital stock, this leads to a positive relation between the expected wage costs and the investment level of a firm. Firms will therefore not be able to appropriate the entire marginal returns on capital and this leads to under-investment.

Our next result shows that the hold-up problem disappears when workers can direct their search towards different types of firms. A sufficient condition for the equilibrium with directed search is that workers (costlessly) observe the capital stock of all firms before they make their applications. This assumption creates a competitive environment in which each job opening needs to offer unemployed workers the same expected income. A firm that increases her investment level may therefore still need to pay a higher wage, but this is now exactly compensated by a larger number of expected applicants and hence a smaller probability that the firm will face a single applicant. From the viewpoint of an individual firm the expected wage costs are therefore independent of her investment level, resulting in efficient investments.

Finally, in a last step we allow firms to announce different reservation profits. In this so-called competing auctions setup, application decisions respond both to capital and the reservation strategy of firms. As long as these variables are freely observable, we find that the equilibrium is efficient and that firms announce their true outside option value. Our efficiency result is therefore not contingent on our choice of the auction rule. When firms have a choice, they select an auction rule in the class of efficient rules.

Our results illustrate the importance of job competition. Nonetheless, the introduction of job competition is not sufficient. In order to attain a (constrained) efficient resource allocation, the labour market needs to generate stronger competition for more attractive jobs. It is therefore crucial that unemployed workers observe all the payoff-relevant information about jobs.

The conclusion that directed search may prevent hold-up problems is not 
entirely new. Acemoglu and Shimer (1999) reached the same conclusion using a model of wage posting. However, their mechanism is entirely different. With wage posting firms choose the wage at the same time as the investment. Hence, when a firm and a worker meet, there is no scope for wage negotiations and thus no scope for hold-ups. In contrast, in our model wages are determined after the investments are made, and the efficient allocation is entirely supported by the competition between rival applicants. It stimulates efficient investments and it prevents that firms a announce reservation bid above the value of their outside option.

Finally, it is well-known that our job auction introduces strong incentives for renegotiation. Consider a worker who is hired at her reservation wage. Once the firm has discharged the other applicants, this worker has a clear incentive to ask for a higher wage. Renegotiation is ruled out in most of the analysis. Nonetheless, in an extension we show that none of our results change if we allow renegotiation by mutual consent. The only additional requirement is that both parties' participation constraint needs to be satisfied at each moment during the relationship. Our model is therefore consistent with a simple model of multilateral bargaining in which workers' surplus share is decided once and for all before the start of production.

The rest of the article is organized as follows. Section 2 introduces the environment and discusses the matching technology. Section 3 characterizes the efficient resource allocation. This is followed in Section 4 by a discussion of the equilibrium with random search. The equilibrium with directed search is described in Section 5 while the equilibrium with posting, a simplified analysis of the mechanism design problem for firms that wish to protect their returns on non-contractible investments, is discussed in Section 6. This section also describes the implications of renegotiation by mutual consent. Finally, Section 7 concludes the paper and discusses directions for future research. 


\section{The Model}

\subsection{Main assumptions}

There is a continuum of workers with measure normalized to one and a larger continuum of firms. All agents are risk-neutral, live forever in discrete time and have a common discount factor $\beta \in(0,1)$. The utility of an agent in period $t$ is equal to her consumption of the unique final good. All agents therefore maximize the value of their expected lifetime income.

Workers are homogeneous and may be in one of two states, employed and producing or unemployed and searching. Firms, on the contrary, are inactive until they buy some capital $k>0$ at constant marginal cost $p$, which allows them to attempt to hire a worker by posting a vacancy. If a firm employs a worker and $k$ units of capital, it produces $f(k)$ units of output per period. The price of this good is normalized to one and $f$ is assumed to be strictly increasing and concave and satisfies the usual Inada conditions with $f(0)=0$.

Finally, at the end of each period the capital stock of an active firm breaks down with probability $s$. After this shock the firm returns to the pool of inactive firms. Likewise, a worker whose job is destroyed becomes unemployed with a flow income that is normalized to zero.

\section{$2.2 \quad$ A model of job auctions}

Our model of the labour market is based on Shimer (1999). In this sequential search model firms auction their jobs to applicants and workers may have to compete for jobs.

Let us start with the application decisions. At the start of a period each unemployment worker can apply for one job. An application strategy defines the probability that a worker applies for a job at each measurable set of firms. Moreover, to capture the notion of a large market economy, we 
assume that all workers adopt the same optimal strategy. In any equilibrium, some vacant jobs therefore attract many applicants, while other identical jobs attract none.

After the application stage is concluded, firms hold job interviews and solicit a wage bid from each applicant. The bid specifies the time path of wages at which the applicant is willing to work. Firms review these bids and decide whether to hire a worker, and if so, which one. The associated wage payments are determined by an auction rule. This rule is known to all participants and initially we assume that contracts are perfectly enforceable. Hence, wages are determined once and for all at the start of a relationship and for the moment we assume that contracts cannot be renegotiated. Finally, if a firm is indifferent between two or more bids, it selects one bid at random. The chosen worker begins her job at the start of the next period.

\subsection{Example: random search}

Further details of the hiring procedure are discussed in Section 3.1. In the remainder of this section we describe the outcome of the application process when workers cannot discriminate between jobs. From the viewpoint of applicants all jobs therefore look identical, and workers will apply for a job at a randomly selected firm.

More precisely, suppose that in some labour market there are $q \in[0, \infty)$ unemployed workers per vacancy seeking employment. If workers cannot discriminate between jobs, $q$ is also the (market) queue length or the expected number of applicants of each vacancy. The probability that a firm receives exactly $n$ applications is then defined by:

$$
\varphi(n, q)=\frac{q^{n} e^{-q}}{n !}
$$


According to (1), a vacant firm will attract at least one applicant with probability $\eta(q)=1-e^{-q}$. This expression is known as the "urn ball matching function". ${ }^{2}$ If firms randomize over applicants, a similar expression may be derived for workers. The probability that a worker is hired is then given by $\mu(q)=\eta(q) / q=\frac{1-e^{-q}}{q}$. It is easy to verify that the urn ball matching technology satisfies all the usual properties: $v \eta(q)$, the mass of vacancies with at least one applicant, is linearly homogeneous in the mass of unemployed workers and vacant jobs, $\eta^{\prime}(q)>0, \mu^{\prime}(q)<0, \lim _{q \rightarrow 0} \eta(q)=\lim _{q \rightarrow \infty} \mu(q)=0$ and $\lim _{q \rightarrow \infty} \eta(q)=\lim _{q \rightarrow 0} \mu(q)=\infty$.

The matching probabilities with directed search are derived in Section 5 . In this case workers can perfectly discriminate among jobs. As a result, the labour market may divide in several submarkets, each with a particular type of a job and the associated (optimal) queue length.

\footnotetext{
${ }^{2}$ The urn ball matching technology was first used by Butters (1977). For recent applications see Moen (1999) or Shimer (1999).
} 


\section{The Efficient Allocation}

We start our analysis with a derivation of the constrained efficient resource allocation. ${ }^{3}$ This allocation is derived using an imaginary social planner who chooses the time path of the market queue length $q$, firms' capital investment $k$ and the unemployment rate $u$ to maximize the discounted value of output minus the costs of vacancy creation.

Formally, the planner's problem can be written as follows:

$$
\begin{aligned}
\max _{\{q(t), k(t), u(t)\}_{t=0}^{\infty}} & \sum_{t=0}^{\infty} \beta^{t}\left[u(t) \mu(q(t)) Y(k(t))-\frac{u(t)}{q(t)}(1-\beta(1-s)) p k(t)\right] \\
\text { s.t. } & u(t+1)=u(t)+s(1-u(t))-(1-s) \mu(q(t)) u(t)
\end{aligned}
$$

where

$$
Y(k(t))=\beta(1-s)\left[\frac{f(k(t))}{1-\beta(1-s)}-p k(t)\right]
$$

To understand the objective function, it is convenient to imagine firms renting capital at a cost $(1-\beta(1-s)) p$. The first term in parentheses then represents the payoff from newly created jobs. Each of these jobs produces $f(k(t))$ units of output per period. Moreover, production starts with one period delay and firms must continue to pay the rental cost of their equipment. The net expected present value of a filled job is therefore equal to $Y(k(t))$ as defined in (4). The second term in parentheses represents the costs of maintaining open vacancies, i.e. the rental cost of capital $(1-\beta(1-s)) p$ times the number of vacancies $u(t) / q(t)$, times the capital used by each vacancy $k(t)$. The feature that it is optimal to have only one type of firm in a market follows from the

\footnotetext{
${ }^{3}$ This section draws on Section 3 in Acemoglu and Shimer (1999).
} 
concavity of $f(k){ }^{4}$ Finally, all payoffs are discounted to the initial period, while the evolution of the unemployment rate $u(t)$ satisfies eqn. (4).

Below we restrict attention to stationary allocations. In a steady state the planner's problem reduces to the maximization of the (constant) shadow value of unemployed workers. This result is summarized in the Proposition below, which reformulates Proposition 1 in Acemoglu and Shimer (1999):

Proposition 1 An efficient steady state solution exists. It is characterized by a pair $\left(q^{S}, k^{S}\right) \in(0, \infty)^{2}$ solving:

$$
\max _{\{k, q\}} \frac{\beta(1-s) \eta(q)\left(\frac{f(k)}{1-\beta(1-s)}-p k\right)-(1-\beta(1-s)) p k}{(1-\beta(1-s)) q+\beta(1-s) \eta(q)} .
$$

Proof. See Appendix.

Maximization problem (5) is not jointly concave in $k$ and $q$. Hence, the firstorder conditions are not sufficient for a maximization. Nonetheless, because the efficient solution is an interior solution, the first-order conditions are necessary, and so they are useful in recognizing inefficient allocations. Using the result that $\eta(q)=1-e^{-q}$, this yields:

Corollary 2 Any efficient allocation $\left(q^{S}, k^{S}\right)$ satisfies:

$$
\begin{gathered}
\frac{\beta(1-s)\left(1-e^{-q^{S}}\right)}{1-\beta(1-s)+\beta(1-s)\left(1-e^{-q^{S}}\right)}\left(\frac{f^{\prime}\left(k^{S}\right)}{1-\beta(1-s)}\right)=p \\
\frac{\beta(1-s)\left(1-e^{-q^{S}}-q^{S} e^{-q^{S}}\right)}{1-\beta(1-s)+\beta(1-s)\left(1-q^{S} e^{-q^{S}}\right)}\left(\frac{f\left(k^{S}\right) / k^{S}}{1-\beta(1-s)}\right)=p .
\end{gathered}
$$

\footnotetext{
${ }^{4}$ Appendix A provides a formal proof of this assertion.
} 
Proof. See Appendix.

Equation (6) characterizes the efficient investment level. The first fraction on the left hand side is the expected current value of a unit of output when the vacancy is first filled. This value is discounted because of both impatience and the risk that the vacancy may break down before it is filled. The second fraction is the discounted marginal product of capital once the vacancy is filled. The left hand side of (6) therefore defines the marginal revenue of an additional unit of capital. In an efficient allocation this must be equal to the marginal cost of capital $p$.

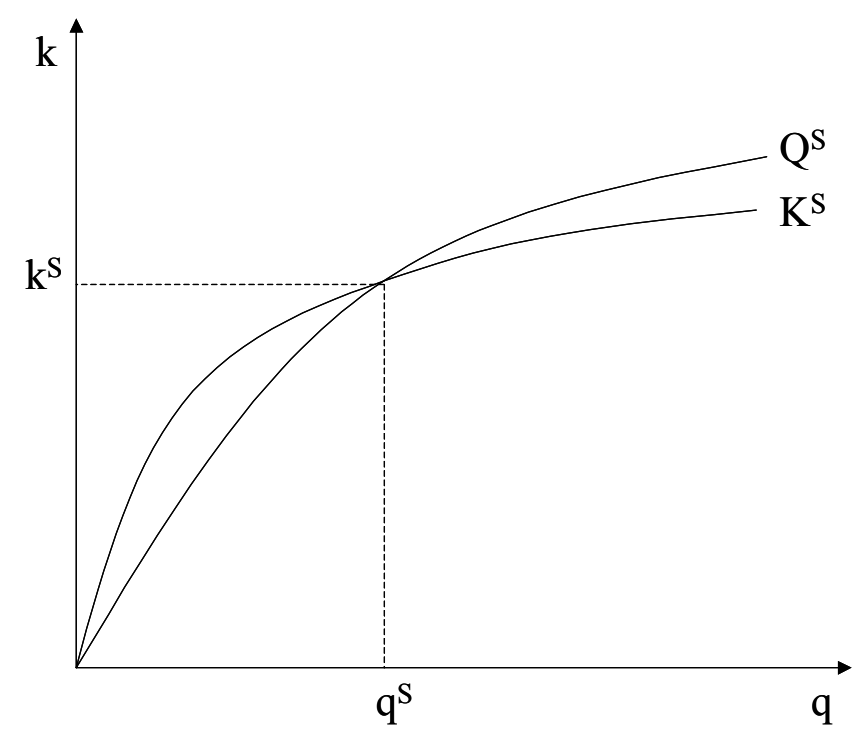

Figure 1: The constrained efficient allocation

The efficient market queue length is defined in (7). The planner chooses $q$ to balance the expected social benefits of an additional vacancy with the costs of creating this vacancy. In doing so, the planner takes into account that an increase in the number of vacancies will reduce the rate at which outstanding vacancies are filled. The net-increase in the mass of new jobs due to the creation of an additional vacancy is therefore equal to $\partial v\left(1-e^{-q}\right) / \partial v=$ $\left(1-e^{-q}-q e^{-q}\right)$. 
The efficient allocation is illustrated in Figure 1. The curves associated with eqs. (6) and (7) are denoted by $K^{S}$ and $Q^{S}$, respectively. Both curves start in the origin and are strictly increasing in $(q, k)$ space. Moreover, for large enough values of $q, Q^{S}$ lies above $K^{S}$ and the two curves intersect at least once on the interior. Hence, as stated in Proposition 1, an efficient allocation always exists. Finally, if there is more than one efficient combination $\left(q^{S}, k^{S}\right)$ and if workers can discriminate among jobs, the planner may decide to open more than one (sub)market. In that case the planner will assign a longer queue to firms with a larger capital stock ${ }^{5}$. In an efficient allocation, capital-intensive jobs are therefore filled at a faster rate than less capital-intensive jobs.

\section{1 efficient vs decentralized allocations}

In the next sections we compare the efficient allocation to the decentralized outcome. The investments in capital are now financed by firms and wages are determined by auctions.

To concentrate on the investment decisions of firms, we initially impose two conditions on the set of auction rules. First, we assume that the auction rules are fair. A job is therefore awarded to the worker who demands the lowest wage. Second, we assume that firms cannot credibly announce a reserve bid above the value of their endogeneous outside option.

Together these two conditions define a set of revenue equivalent auction rules. Moreover, each of these rules would induce an efficient resource allocation if the value of productivity were exogeneous (e.g. Shimer, 1999). For convenience, we shall consider the example of a sealed bid second prize

\footnotetext{
${ }^{5}$ This follows immediately from the feature that $Q^{S}$ and $K^{S}$ both have a strictly positive slope. Thus, if there exist two efficient allocations, say $\left(k_{1}^{S}, q_{1}^{S}\right)$ and $\left(k_{2}^{S}, q_{2}^{S}\right)$, and $k_{1}^{S}>k_{2}^{S}$ then it must be true that $q_{1}^{S}>q_{2}^{S}$.
} 
auction. ${ }^{6}$ Also, we shall assume that workers do not know the total number of applicants when they formulate their wage demands. This is only revealed ex post when the firm puts her offers "on the table". The advantage of this setup is that workers have a unique (weakly) dominant wage bid which is equal to their outside option.

In the next two sections we use this setup to study the outcome when workers cannot discriminate among jobs ("random search") and when they have perfect information about the capital investments of firms ("directed search"). The case in which firms also choose and announce their reservation profit is discussed in Section 6.

\section{Random search}

The purpose of this section is to formalize the scope for hold-up problems. With random search there is no relationship between the investment level of a firm and the application decisions of workers. All vacant firms expect the same number of applicants and when a firm decides how much to invest it will take this number as given. The notion of an equilibrium is therefore similar to Davis (2002).

Formally, let $\mathcal{K}$ denote the set of equilibrium investment levels and let the variable $J^{V}(k)$ denote the expected value of a vacant job with $k$ units of capital. A steady state equilibrium with random search must then satisfy the following conditions: (i) Firms have rational expectations about q. (ii) The investment level of a new entrant maximizes her expected profits $J^{V}\left(k^{\prime}\right)-p k^{\prime}$. (iii) New entrants make zero profits. (iv) Match formation is voluntary. (v) The wage payments of workers correspond to the equilibrium of a sealed bid second prize auction.

\footnotetext{
${ }^{6}$ The same setup is used in Shimer (1996). For an analysis of the more realistic case of a first prize auction see Shimer (1999).
} 
The model is solved backwards starting with wages, and for the moment I assume that condition (iv) is always satisfied. ${ }^{7}$

\subsection{Wages}

Consider a vacant firm with $k$ units of capital that attracts $n>0$ applicants. In the following we denote the contractual payoffs of a firm and a worker by $J^{F}(k, n)$ and $J^{E}(k, n)$, respectively. These payoffs are discounted to the start of the first period of production. Moreover, we denote the joint payoffs of a firm-worker pair by $S(k)$, so that $S(k)=J^{F}(k, n)+J^{E}(k, n)$, while $J^{U}$ denotes the asset value of an unemployed worker

It is easy to demonstrate that $J^{U}$ is also the unique weakly dominant wage bid of an applicant (e.g. Shimer 1996). Hence, since workers are identical, there are two possible outcomes. In the first case, the firm has a single applicant who submits a wage bid equal to $J^{U}$. The firm hires the applicant and agrees to a wage stream with value $J^{E}(k, 1)=S(k)-J^{V}(k) .^{8}$ In the second case, the firm has several job candidates. Each of these applicants submits a wage bid equal to $J^{U}$ and the firm selects one candidate at random and offers this worker a contract with value $J^{E}(k, n)=J^{U} \forall n>1$. Since $S(k)=J^{F}(k, n)+J^{E}(k, n)$, the outcome of the auction can thus be summarized as follows:

\footnotetext{
${ }^{7}$ When I characterise the investment decisions, I will show that this is indeed an equilibrium feature. In equilibrium it is never optimal for a firm to create a job that is subsequently refused by all workers.

${ }^{8}$ Given that agents are risk neutral, they are indifferent between contracts with the same expected values $J^{F}(k, n)$ and $J^{E}(k, n)$. Moreover, the timing of the payments is irrelevant because contracts are perfectly enforceable and cannot be renegotiated. This last assumption is relaxed in Section 6.2.
} 


$$
J^{E}(k, n)=\left\{\begin{array}{cc}
S(k)-J^{V}(k) & \text { if } n=1 \\
J^{U} & \text { if } n>1 .
\end{array}\right.
$$

Similarly,

$$
J^{F}(k, n)=\left\{\begin{array}{cc}
J^{V}(k) & \text { if } n=1 \\
S(k)-J^{U} & \text { if } n>1 .
\end{array}\right.
$$

Hence, the firm receives the entire value of the surplus if it has at least two applicants. Otherwise the surplus accrues to the single applicant. ${ }^{9}$

\subsection{Asset values}

We are now in a position to derive the value functions for the unattached agents. These functions depend on the value of the future matches in which an agent will be involved, and on the probability that the associated match surplus accrues to the firm or the worker. The value of $S(k)$ is defined by the following standard Bellman equation:

$$
S(k)=f(k)+\beta\left[(1-s) S(k)+s J^{U}\right] .
$$

According to (10) the joint value of a match is equal to the payoffs in the current period, $f(k)$, plus the expected discounted payoffs in the next period.

\footnotetext{
${ }^{9}$ As explained in the Introduction, the standard approach is to assume ex post wage bargaining. In those models the bargaining power of a firm and a worker is fixed. In contrast, in our model the bargaining strength is endogeneously assigned to either the firm or the worker.
} 
The probability that a match survives is equal to $(1-s)$, in which case both parties continue to obtain $S(k)$. With complementary probability $s$, however, the capital equipment is destroyed. The match will be dissolved and the firm becomes inactive with payoffs equal to zero, while the worker returns to the pool of unemployed with payoffs equal to $J^{U}$. Rearranging terms, this yields the following expression:

$$
S(k)=\frac{f(k)+s \beta J^{U}}{1-\beta(1-s)}
$$

Next, consider the expression for $J^{V}(k)$. With random search the number of applicants of a firm is distributed according to (1). Moreover, the expected payoffs for each realization of $n$ are defined by (9). The asset value of a vacant firm can therefore be expressed as the weighted sum of three contingent payoffs:

$$
J^{V}(k)=\beta(1-s)\left[\left(e^{-q}+q e^{-q}\right) J^{V}(k)+\left(1-e^{-q}-q e^{-q}\right)\left(S(k)-J^{U}\right)\right] .
$$

First of all, with probability $e^{-q}$ the firm receives no applications and remains vacant. Second, with probability $q e^{-q}$ the firm receives exactly one application and settles for a payoff equal to $J^{F}(k, 1)=J^{V}(k)$, leaving the surplus to the worker. Finally, with complementary probability $1-e^{-q}-q e^{-q}$ the firm has more than one applicant. In this case the firm retains the surplus and receives $J^{F}(k, n)=S(k)-J^{U}$. Finally, in all three events the payoffs need to be discounted to account for time preference and the risk of breakdown.

The value function of an unemployed worker is slightly more complicated, as vacant firms may have different capital stocks:

$$
J^{U}=\beta\left[\left(1-e^{-q}\right) J^{U}+e^{-q} \int\left[(1-s)\left(S(k)-J^{V}(k)\right)+s J^{U}\right] d G(k)\right] .
$$


With random search the value of an unemployed worker therefore depends on the entire distribution of capital stocks across vacant firms, which I denote by $G(k)$, and on the number of applicants with whom the worker will compete. It is easy to show that a worker is the only applicant with probability $e^{-q}$. In this case the worker is hired and unless the capital equipment breaks down she receives a payoff equal to $J^{E}(k, 1)=S(k)-J^{V}(k) .{ }^{10}$ The probability that the firm has at least one additional applicant is thus equal to $1-e^{-q}$, and in this case the worker receives $J^{U}$ regardless whether she is hired or not.

\subsection{Equilibrium}

Given the payoff functions for firms and workers, we can now derive the equilibrium.

\subsubsection{Investments and hold-up}

Our first task is to derive the profit-maximizing investment level(s) for a given value of $q$. To solve this problem, we substitute the solution for $S(k)$ into the right-hand side of (12):

$$
J^{V}(k)=\frac{\beta(1-s)\left(1-e^{-q}-q e^{-q}\right)}{1-\beta(1-s)+\beta(1-s)\left(1-e^{-q}-q e^{-q}\right)}\left[\frac{f(k)-(1-\beta) J^{U}}{1-\beta(1-s)}\right] .
$$

\footnotetext{
${ }^{10}$ Notice that this interpretation is based on the auxiliary assumption that payment start at the beginning of production period. In reality, however, contracts are enforceable and all payments could in principle be made immediately after the contract is signed. In that case the worker would receive $\beta(1-s)\left(S(k)-J^{V}(k)\right)$ in the first period and $J^{U}$ in the next period in case the match breaks down. The expected value of payments is the same under both interpretations.
} 
The above equation defines $J^{V}(k)$ as the expected profit from hiring a worker at her reservation wage $(1-\beta) J^{U}$. The probability of this event is equal to $1-e^{-q}-q e^{-q}$. Moreover, from our discussion of (13) we know that the reservation wage of workers is not affected by the investment decision of a single firm.

The derivation of the equilibrium investments is now straightforward. Each firm that enters the market maximizes expected profits $J^{V}\left(k^{\prime}\right)-p k^{\prime}$ taking $q$ and the investment decisions of all other firms as given. This leads to the following first order condition: ${ }^{11}$

$$
\frac{\beta(1-s)\left(1-e^{-q}-q e^{-q}\right)}{1-\beta(1-s)+\beta(1-s)\left(1-e^{-q}-q e^{-q}\right)}\left[\frac{f^{\prime}(k)}{1-\beta(1-s)}\right]=p .
$$

Equation (15) is our first equilibrium condition. It defines the investment level of firms as a strictly increasing function of the likelihood that a firm attracts at least two applicants. In any equilibrium firms therefore make the same investment and $G(k)$ is degenerate. Furthermore, what is more important, a comparison with (6) shows that firms underinvest in capital.

Lemma 3 For any given value of $q<\infty$, firms under-invest in capital

Proof. See Appendix.

The intuition for this result is straightforward. With homogeneous agents on both sides of the market, all jobs that attract at least one applicant will be filled. The social marginal returns from an investment in capital are therefore proportional to $\eta(q)=1-e^{-q}$. However, firms only consider their own private marginal returns which are proportional to $1-e^{-q}-q e^{-q}$. Firms therefore

\footnotetext{
${ }^{11}$ Since $f(k)$ is strictly concave, the second order conditions are always satisfied.
} 
disregard the share of the returns that may accrue to a single applicant and since $f(k)$ is strictly concave, this gives rise to underinvestment.

It is important to understand the origin of this hold-up problem. With random search $q$ is the same for all firms. The probability that a firm attracts one or more applicants is therefore unrelated to the investment level of the firm. However, the implicit cost of search, in terms of foregone output, increases with the investment level of the firm. As a result, both the surplus of a job and the income of a single applicant $S(k)-J^{V}(k)$ increase with $k$, and when a firm decides how much to invest it will anticipate that a share of the marginal returns of the investment may accrue to the worker. ${ }^{12}$

Finally, it is easy to demonstrate that the actual chance of a hold-up is particularly strong at low values of $q$. With a small number of expected applicants, firms face a high probability of meeting exactly one applicant. ${ }^{13}$ The private marginal returns from an investment are therefore low compared to the social marginal gains. In contrast, when $q$ approaches infinity, firms receive more than one applicant with probability 1 and both returns coincide.

\subsubsection{Entry}

The derivation of the entry condition is entirely standard. First of all, since $G(k)$ is degenerate, $J^{U}$ simplifies to:

$$
J^{U}=\frac{\beta(1-s) e^{-q}}{1-\beta(1-s)+\beta(1-s) e^{-q}}\left[\frac{f(k)-(1-\beta(1-s)) J^{V}(k)}{1-\beta}\right],
$$

which has a similar interpretation as (14).

\footnotetext{
${ }^{12}$ This is similar to the hold-up problem in Davis (2001), except that he examines a model with pairwise matching and ex post bargaining. As a result, in his model all workers obtain a share of the returns on capital.

${ }^{13}$ The conditional probability that a firm attracts exactly 1 applicant is equal to $q e^{-q} /\left(1-e^{-q}\right)$. After applying l'Hopital's rule, it follows that this probability goes to1 when $q$ approaches zero.
} 
Next, we need to substitute (16) into the right-hand side of (14). The resulting expression can be solved for $J^{V}(k)$ and invoking the free entry condition $J^{V}(k)-p k=0$ we obtain:

$$
\frac{\beta(1-s)\left(1-e^{-q}-q e^{-q}\right)}{1-\beta(1-s)+\beta(1-s)\left(1-q e^{-q}\right)}\left(\frac{f(k) / k}{1-\beta(1-s)}\right)=p .
$$

This free entry condition coincides with (7). Hence, conditional on an efficient value for the capital stock, $k^{S}$, the labour market will generate the efficient number of jobs. However, from the preceding discussion of investments we know that the reverse does not hold. Given an efficient value for the market queue length $q^{S}$, firms are not willing to adopt the efficient capital stock. The equilibrium with random search is therefore never efficient.

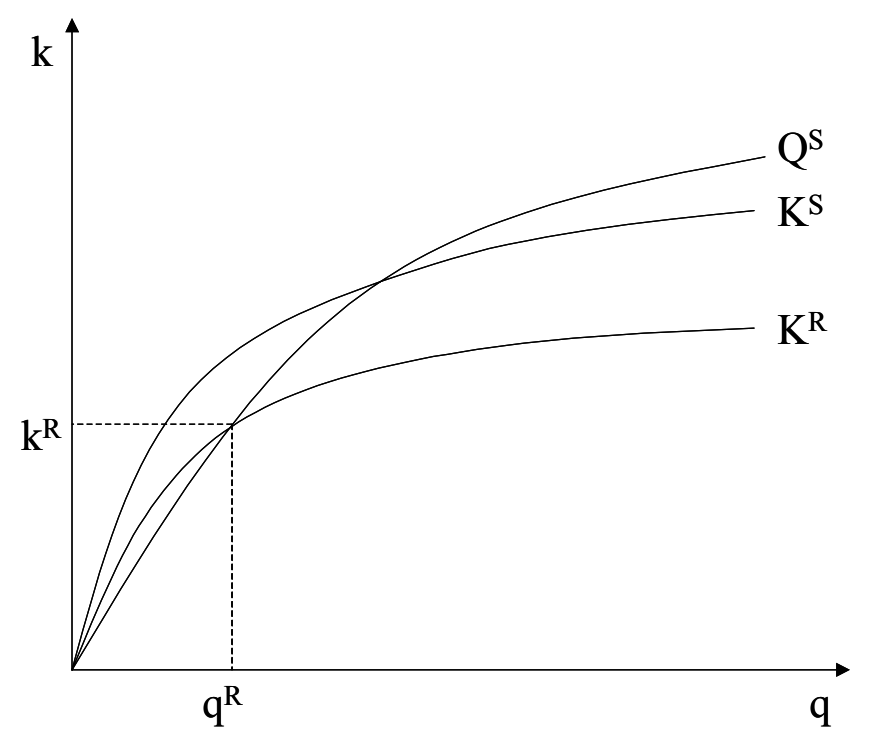

Figure 2: The equilibrium with random search

This feature is illustrated in Figure 2. The curve associated with free entry condition (17) is denoted by $Q^{R}=Q^{S}$, while the investment locus associated with $(15)$ is denoted by $K^{R}$. Due to the hold-up problem this locus 
lies entirely below $K^{S}$. The decentralized equilibrium with random search, denoted by the pair $\left(k^{R}, q^{R}\right)$, is therefore never efficient. Finally, if $k^{S}$ and $q^{S}$ are small, the investment locus $K^{R}$ may lie entirely below the free entry locus $Q^{R}$. In this case there exists no (interior) equilibrium.

To rule out this last case, it suffices to impose a mild restriction on the concavity of $f(k)$. In particular, let $\epsilon(k)$ denote the elasticity of $f(k)$ with respect to $k$, so that $\epsilon(k)=f^{\prime}(k) k / f(k)$. A sufficient condition for the existence of an equilibrium is then given by:

Condition $1 \lim _{k \rightarrow 0} \epsilon(k)>1-\beta(1-s)$.

The properties of the equilibrium are summarized below.

Proposition 4 (Existence) Given Condition 1, an equilibrium with random search always exists.

Proposition 5 (Efficiency) The equilibrium with random search never coincides with an efficient allocation. Either firms underinvest and $k^{R}<k^{S}$, or entry is too low and $q^{R}>q^{S}$.

Proposition 6 (Uniqueness) If $\epsilon(k)$ is non-increasing in $k$, the equilibrium is unique and firms underinvest in capital.

Proof. See Appendix.

Proposition 5 formalizes the scope for hold-ups in our economy. This result contrasts sharply with the efficiency of our auction rule in the standard search environment (e.g. Kultti, 1998 and Shimer, 1996). With ex ante investments firms' entry decisions are still optimal for a given value of capital. But firms anticipate that the expected wage costs increase with the investment level and this results in an inefficient choice of capital. 
The explanation for the efficient entry margin is provided in Shimer (1996). Namely, with a second prize auction applicants are paid their actual marginal product. Suppose that a firm receives a single applicant. By contacting the firm, the applicant raises the joint wealth of the firm-worker pair from $J^{V}(k)+J^{U}$ to $S(k)$. In order to hire the worker the firm would thus be willing to pay at most $S(k)-J^{V}(k)$. In contrast, if the firm receives more than one applicants, only one new job is created. The marginal productivity of each individual worker is thus equal to zero, and the firm would not be willing to pay any of these workers more than her reservation value.

There also exists a clear relation with the so-called Hosios condition. According to this condition, wages correctly reflect productivity if workers' share of the match surplus is equal to the elasticity of the matching function with respect to $u$. With the urn ball matching technology this elasticity is given by $\frac{\eta^{\prime}(q) q}{\eta(q)}=\frac{q e^{-q}}{1-e^{-q}}$. But this is nothing else than the conditional probability that the surplus of a job accrues to the worker (see footnote 11). ${ }^{14}$ Hosios' condition is therefore satisfied. Nonetheless, with random search

\footnotetext{
${ }^{14}$ This generalises an important result in Mortensen (1982). For the case of a pairwise linear matching technology, Mortensen showed that the efficient allocation can be decentralised if the property rights to a match are assigned to the agent who iniates the contact. The usefullness of this result was later questioned on two grounds (e.g. Pissarides, 2000). First, with pairwise matching it is often not possible to determine who initiated the match. Second, Mortensen's matching technology does not exhibit congestion externalities. The urn ball matching technology does exhibit these externalities and efficiency is obtained under a similar rule. Namely, when the property rights are assigned to the agent on the short side. The reason that Mortensen's rule still generates efficiency is also easily explained. When creating a job, firms disregard the returns that accrue to a single applicant. As a result, the private marginal returns are equal to $\left(1-e^{q}-q e^{-q}\right)$ times the surplus of the match. However, this is exactly the social marginal return from job creation since $\partial v\left(1-e^{-q}\right) / \partial v=\left(1-e^{q}-q e^{-q}\right)$. In other words, the fact that firms disregard the returns of a single applicant compensates for the reduction in the matching rate of existing vacancies. The congestion externality is therefore perfectly internalised.
} 
this surplus share creates a hold-up problem. The equilibrium allocation is therefore never efficient.

\section{Directed search}

In this section we study the same environment as before. But in contrast to Section 4, we now assume that workers have perfect information about the capital stock of all the advertised jobs.

This change of the information structure has two important implications. First of all, because workers can discriminate between jobs, the labour market may divide into several submarkets. Firms with different jobs therefore no longer need to attract the same number of expected applicants.

Second, given their knowledge about the queue length for each type of job, unemployed workers are able to compute the expected income from an application at any of the vacant firms. Hence, if workers decide to apply for different types of jobs, then the queue lengths must be such that workers are indifferent between these jobs.

This arbitrage relationship is a typical feature of models with directed search. To understand how it affects our results, it is useful to consider what happens if a firm (or formally, an infinitesimally small mass of firms) deviates to a higher investment level. With random search, the higher investments raised the income of a single applicant, $S(k)-J^{V}(k)$, but unemployed workers could not respond to this incentive because they had no information about the vacant jobs. In contrast, with directed search workers observe the deviation. The deviant firms will therefore attract a longer queue of applicants who all wish to appropriate the larger surplus. Moreover, in the new outcome workers are indifferent between the deviant firms and the rest of the firms. The expected wage costs are therefore not affected by the higher investment - the higher remuneration of a single applicant is exactly 
compensated by the longer queue and the lower probability to meet a single applicant - and deviant firms are able to appropriate the full marginal returns on their investment

Below we show that this mechanism creates a competitive environment in which firms make constrained-efficient investments. The analysis exploits the reduced-form characterization of competitive search equilibria developed by Moen (1997). We denote the expected number of applicants of a firm with $k$ units of capital by $q(k)$. Moreover, compared to the previous section, we impose two stronger conditions on the equilibrium allocation: $(i-a)$ The common application strategy of unemployed workers maximizes their actual expected income $J^{U}$ for any arbitrary distribution $G(k)$. (i-b) Firms' beliefs about $q(k)$ are consistent with rational expectations beginning at any decision node and for all feasible values of $k$. This last restriction is needed to rule out situations in which firms would fail to deviate to a profitable investment level because they incorrectly conjecture too few workers would apply. Conditions $(i-a)$ and $(i-b)$ replace condition (i) in Section 4. The rest of the conditions is the same as before.

\subsection{Analysis}

We start the analysis by writing the Bellman equations. With targeted applications, the value of a vacant job with $k$ units of capital satisfies

$$
\begin{aligned}
J^{V}(k)=\beta(1-s)\left[\left(e^{-q(k)}+q(k) e^{-q(k)}\right) J^{V}(k)+\right. \\
\\
\left.\left(1-e^{-q(k)}+q(k) e^{-q(k)}\right)\left(S(k)-J^{U}\right)\right],
\end{aligned}
$$

where $q(k)$ is the job-specific queue length.

Similarly, the value of an application at a firm with capital-intensity $k$, $J^{U}(k)$, satisfies: 


$$
J^{U}(k)=\beta\left(\left(1-e^{-q(k)}\right) J^{U}+e^{-q(k)}\left((1-s)\left(S(k)-J^{V}(k)\right)+s J^{U}\right)\right) .
$$

The derivation of (19) parallels equation (13), with the value of an unemployed worker now defined by the highest value she can obtain while unemployed. That is,

$$
J^{U}=\sup _{k \in \mathcal{K}} J^{U}(k)
$$

Finally, it is easy to show that all jobs that attract some workers need to offer the same maximal utility $J^{U}$. Suppose some jobs would offer a smaller payoff. In that case workers could gain by redirecting their search to the jobs with the highest payoffs and this would violate condition $i$-a. Hence, in equilibrium all submarkets yield the same expected income $J^{U}$. This last feature allows us to solve equations (18)-(19) for all $k \in \mathcal{K}$. This procedure yields a payoff function

$$
J^{V}(k)=\frac{\beta(1-s)\left(1-e^{-q(k)}-q(k) e^{-q(k)}\right)}{1-\beta(1-s)+\beta(1-s)\left(1-q(k) e^{-q(k)}\right)}\left[\frac{f(k)}{1-\beta(1-s)}\right]
$$

for firms offering a job with $k \in \mathcal{K}$ units of capital, and

$$
J^{U}=\frac{\beta(1-s) e^{-q(k)}}{1-\beta(1-s)+\beta(1-s)\left(1-q(k) e^{-q(k)}\right)}\left[\frac{f(k)}{1-\beta}\right]
$$

for workers who apply for these jobs.

On the basis of the above equations we can immediately conclude that firms continue to create an efficient number of jobs. To obtain this result, it 
suffices to substitute $(21)$ into the zero profit condition $J^{V}(k)-p k=0$. This yields

$$
\frac{\beta(1-s)\left(1-e^{-q(k)}-q(k) e^{-q(k)}\right)}{1-\beta(1-s)+\beta(1-s)\left(1-q(k) e^{-q(k)}\right)}\left[\frac{f(k) / k}{1-\beta(1-s)}\right]=p,
$$

which coincides with (7).

The difference with the previous section concerns the choice of capital. Namely, with directed search firms correctly anticipate the best reply of unemployed workers to changes in their investment strategy. This response is governed by (22). For a given value of $J^{U}$, this equation defines a strictly positive relationship between the capital stock and the queue length in each sub-market. Moreover, since $J^{U}$ is not affected by the decisions of a single firm, the same relationship also defines the queue length that results if some firm deviates by offering a job with $k^{\prime} \notin \mathcal{K}$ units of capital. Denote this relationship by $q\left(k ; J^{U}\right)$. From (22) it follows immediately that $q\left(k ; J^{U}\right)$ is continuous, strictly increasing in $k$ and strictly decreasing in $J^{U}$ on $(\underline{k}, \infty) \times$ $(0, \infty)$, where $\underline{k}$ is defined by $J^{U}=\beta(1-s)(f(\underline{k}) /(1-\beta))$. Furthermore, for capital levels below this threshold, $J^{V}(k)<J^{U}$ for all $q \geq 0$. In equilibrium no worker will therefore apply for these jobs, and so $q(k)=0 \forall k<\underline{k}$.

We can now formalize Condition $i-b$ by requiring that firms' beliefs about $q(k)$ are consistent with $q\left(k ; J^{U}\right)$ for all values of $k$, including the values of capital that are not actually observed in equilibrium. ${ }^{15}$ Individual firms take this relationship as given and choose $k$ to maximize profits. Let $J^{V}\left(k, q\left(k ; J^{U}\right)\right)$ denote the asset value of a vacancy given the equilibrium relation $q\left(k ; J^{U}\right)$.

\footnotetext{
${ }^{15}$ Since workers have perfect information, the queue length associated with each capital level $k^{\prime} \notin \mathcal{K}$ becomes instantly observable as soon as a firm deviates to offer this capital stock. It seems reasonable therefore to assume that the out-of-equilibrium beliefs of firms are consistent with $q\left(k ; J^{U}\right)$.
} 
Profit maximization and the assumption of free entry of firms then imply that in equilibrium the following condition must hold:

$$
J^{V}\left(k, q\left(k ; J^{U}\right)\right)-p k \leq 0 \forall k,
$$

with equality if $k \in \mathcal{K}$.

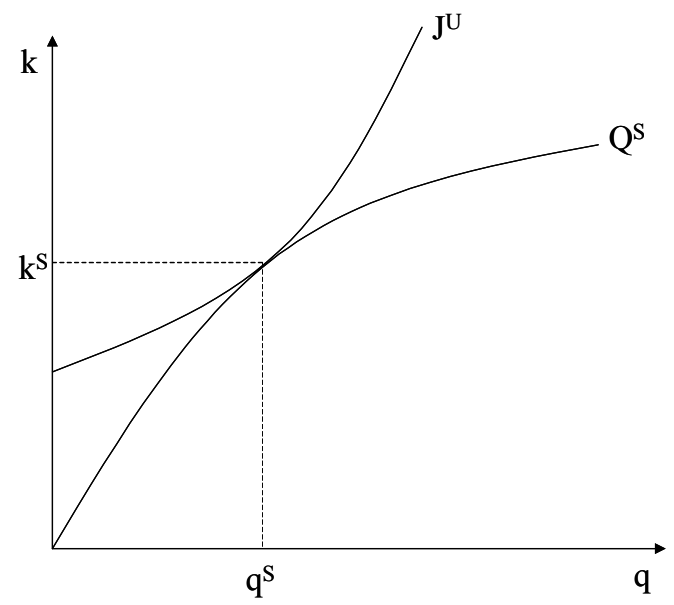

Figure 3: The equilibrium with directed search

The equilibrium with directed search is depicted in Figure 3. The curve $Q^{S}$ is the socially efficient entry locus. As explained before, this curve starts in the origin and is strictly increasing on the whole domain $(q, k) \in(0, \infty)^{2}$. Moreover, at $(q, k)$ combinations to the right of this locus firms make strictly positive profits, while points above this curve correspond to losses. Workers, on the contrary, value high investment levels and short queues. Their indifference curves have a positive slope, and indifference curves that are located further away from the origin correspond to higher values of $J^{U}$. According to condition (23), equilibrium allocations therefore correspond to a point of tangency between the zero profit locus of firms and the highest attainable 
indifference curve of workers, denoted by $\left(k^{D}, q^{D}\right)=\left(k^{S}, q^{S}\right) \cdot{ }^{16}$

This feature of the model allows us to characterize equilibrium allocation as the outcome of a simple constrained optimization problem:

Lemma 7 The pair $\left(q\left(k ; J^{U}\right), \mathcal{K}\right)$ with elements $k^{D} \in \mathcal{K}$ and $q^{D}=q\left(k^{D} ; J^{U}\right)$ is a steady-state equilibrium with directed search iff $\left(q^{D}, k^{D}\right)$ solves:

$$
J^{U}=\max _{\{k, q\}} \frac{\beta(1-s) e^{-q}}{1-\beta(1-s)+\beta(1-s)\left(1-q e^{-q}\right)}\left(\frac{f(k)}{1-\beta}\right)
$$

subject to:

$$
\frac{\beta(1-s)\left(1-e^{-q}-q e^{-q}\right)}{1-\beta(1-s)+\beta(1-s)\left(1-q e^{-q}\right)}\left(\frac{f(k) / k}{1-\beta(1-s)}\right)-p \geq 0
$$

The proof of Lemma 7 is standard. Suppose that firms offer jobs with a lower capital-intensity $k^{\prime}<k^{D}$. This case is illustrated by point $D=\left(k^{\prime}, q^{\prime}\right)$ in Figure 4. It is easy to show that this outcome cannot be an equilibrium. Consider a firm that deviates from the alleged equilibrium by investing an amount $k^{D}$. From our previous discussion, we know that the firm will attract a queue of applicants of length $q^{D E V}$. Moreover, the point $\left(k^{D}, q^{D E V}\right)$ lies below the free entry locus which shows that the expected profits of the deviant firm are positive. Hence, the combination $\left(k^{\prime}, q^{\prime}\right)$ cannot be an equilibrium and firms will continue to create jobs with $k^{D}$ units of capital until the

\footnotetext{
${ }^{16}$ Our restrictions on the production technology are not sufficient to guarantee that the zero-profit curve is concave. As a result, there may be multiple equilibrium allocations. However, this is not important for the analysis since each of these allocations must correspond to a point of tangency between the free entry locus and the highest attainable indifference curve. The equilibrium welfare level of workers is thus uniquely determined.
} 
queue length for these jobs is reduced to $q^{D}$. At this point, the workers' indifference curve is tangent to the free entry locus $Q^{S}(k)$ and no firm can gain by deviating from this allocation as $J^{V}\left(k, q\left(k ; J^{U}\right)\right)-p k<0 \forall k \neq k^{D}$. Hence, in our example $\left(k^{D}, q^{D}\right)$ is the unique equilibrium and this pair solves optimization problem $P 1$ in Lemma 7.

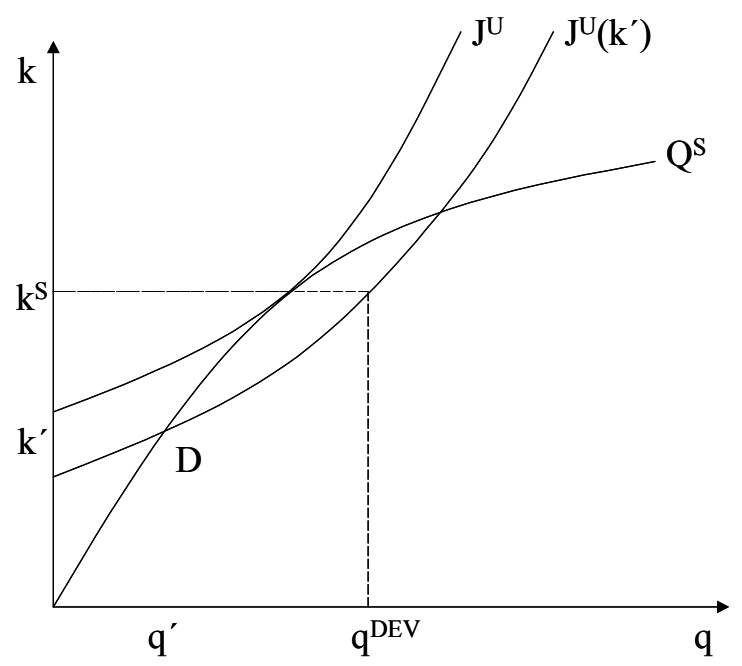

Figure 4: Profitable deviations

\section{$5.2 \quad$ Efficiency}

We are now in a position to derive our main efficiency result. According to Lemma 7 , the equilibrium investment decisions of firms maximize the expected income of unemployed workers, subject to the condition that entrants make zero profits. Moreover, we know that the free entry condition is efficient because applicants are paid their actual marginal product. Hence, as in the planner's solution, firms' investments maximize the shadow value of unemployed workers. This leads to our main efficiency result: 
Proposition 8 If $\left(q\left(k ; J^{U}\right), \mathcal{K}\right)$ is an equilibrium with directed search with elements $k^{D} \in \mathcal{K}$ and $q^{D}=q\left(k^{D} ; J^{U}\right)$, then $\left(q^{D}, k^{D}\right)$ is an efficient allocation as defined in Proposition 1. Conversely, if $\left(q^{S}, k^{S}\right)$ is an efficient allocation as characterized in Proposition 1, then there exists an equilibrium with directed search such that $k^{S} \in \mathcal{K}$ and $q^{S}=q\left(k^{S} ; J^{U}\right)$.

Proof. See Appendix.

The difference with Proposition 4 is that firms make efficient investments. The ability of workers to direct their search to firms with different capital stocks therefore resolves the holdup problem. Namely, it allows firms to increase their investments and attract more applicants without incurring higher expected wage costs. In a neighbourhood around the equilibrium firms therefore acquire the entire marginal returns on their investments. Together with the efficiency of the entry margin this ensures that firms make efficient investments.

\section{Posting and renegotiation}

The previous sections identified the two necessary conditions for efficiency. In equilibrium workers need to be paid their (actual or expected) shadow value and unemployed workers need to be able to direct their search to firms with different capital stocks.

So far, the first condition is satisfied because firms could not commit to a reservation bid above the value of their outside option. Furthermore, we assumed that contracts are perfectly enforceable and ruled out renegotiation. In this section we show that both assumptions can be relaxed without changing our main efficiency result. 


\subsection{Posting}

Suppose that firms can credibly announce any reservation bid and let us denote the optimal reserve bids by $\pi(k)$. The next proposition shows that this endogenous choice of auction rules does not change our results as long as workers can costlessly observe the reserve bids before they make their application decisions. Formally ${ }^{17}$

Proposition 9 Suppose firms can credibly announce their reservation bids and unemployed workers can observe both the reserve bids and the capital stock of firms. Then, the set of equilibria coincides with the set of efficient allocations as characterized in Proposition 1 and firms announce their outside option values, so that $\pi\left(k^{S}\right)=p k^{S}$.

Proof. See Appendix.

Hence, if firms have a choice, they will opt for an auction rule in our class of efficient rules. Proposition 9 therefore corroborates our earlier results.

The result that firms prefer to announce their true outside option value is similar to the predictions of the competing auction models of McAfee (1993), Peters $(1997,2001)$ and Julien, Kennes and King (2000). ${ }^{18}$ However, in these studies the value of matches is determined by exogenous factors. The value of Proposition 9 is therefore that it extends these results to an environment with ex ante investments. In particular, it shows firms do not intend to protect

\footnotetext{
${ }^{17}$ We implicitly extend the restriction on the out-of-equilibrium beliefs of firms to all feasible $(\pi, k)$ combinations, so that firms correctly anticipate the queue length for any choice of the reserve bid. For more details see Appendix D.

${ }^{18}$ McAfee (1993) and Peters (1997) study pricing behaviour in retail markets. Julien et al. (2000) apply a similar setup to labour markets. However, in their model workers commit to and announce reservation wages and firms select a worker to whom they offer the job. In their model the role of workers and firms is therefore reversed. Finally, in Peters (2001) the valuation of the object is private information of the buyers.
} 
their returns on capital by posting high reservation profits. A reservation bid $\pi(k)>p k$ would decrease the wage of a single applicant and prevent ex post rent-sharing. But the overall effect on profits would be negative as firms would attract fewer applicants.

\subsection{Renegotiation by mutual consent}

The last issue concerns the enforceability of the wage agreements. Under the equilibrium wage rule one of the two parties is kept at her reservation value throughout the entire relationship. The second-prize auction therefore creates a strong incentive for renegotiation once the parties have consummated their match. For instance, an employee who was chosen among a total of $n$ applicants, may try to negotiate a higher wage once the firm has dismissed the alternative $n-1$ applicants.

So far, renegotiation was ruled out by assumption. However, this assumption is unnecessarily strong. All that is needed is that renegotiation cannot be imposed unilaterally by one of the parties. With a proper treatment of the outside options this eliminates renegotiation in our model (e.g. Malcomson et al. (1993) or Malcomson (1998)). The only requirement is that the contractual payments need to satisfy the participation constraint of both agents at each moment during their relationship. When this condition is satisfied, renegotiation is a pure redistribution that will be refused by the party that is entitled to the surplus. Hence, when we allow for renegotiation by mutual consent, the timing of payments matters, but this does not change any of our efficiency results. 


\section{Concluding Remarks}

In this paper we have shown that competition among rival applicants may prevent hold-ups in markets with frictions. The analysis built on the competing auction literature pioneered by McAfee and Preston (1993). Our main contribution is that we extend this framework to an environment in which the productivity of employment relationships depends on ex ante investments by firms. We show that this creates a scope for hold-ups. Moreover, following the suggestion of Acemoglu and Shimer (1999) we proof that the equilibrium is efficient if workers can direct their search to different jobs.

There are many interesting ways to extend the analysis. One option is to consider one-sided investments by workers. In this environment ex post bargaining may lead to over-investment rather than under-investment (Moen (1999)). The reason is that workers create a negative externality if they invest more to jump ahead of other workers in the queues. With auctions this effect should disappear. Since workers are valued efficiently, there is no difference between the private and the social marginal gains from human capital and workers should choose the optimal investment level.

Alternatively, one could consider complementary investments by firms and workers. In that model the returns on capital depend on workers' investment in human capital, while vice versa the returns on education and training will depend on firms' investment in capital. Under ex post wage bargaining this strategic complementarity compounds the inefficiencies of one-sided investments (Acemoglu (1996) and Masters (1998)). An issue that is not yet resolved is whether job auctions or wage posting can reduce or eliminate hold-up problems in this environment.

Thirdly, one could consider the role of private information. In our model auctions are equivalent to wage posting whenever workers have perfect information about jobs. Firms could simply post the expected wage costs and 
hire a randomly selected candidate. This equivalence breaks down if workers are risk averse - because auctions are more risky than posting —, or if the number of agents on either side of the market is finite (Julien, Kennes and King (2001)). So far, however, the role of the information structure has not been studied in detail. It is easy to see that the information structure matters. Consider for example the case that unemployed workers observe wages, but not investments. In that case firms will opt for wage posting. This mechanism allows firms to appropriate the entire marginal returns from investments in capital, while auctions lead to hold-ups. Reversely, if workers make ex ante investments and if the resulting skill level is private information firms may prefer auctions. The reason is that auctions elicit the private information from workers. With wage posting, on the contrary, this is only feasible if firms can post a menu of contracts that induces workers to selfselect in different submarkets.

Finally, one may consider the role of education as a pure screening device. In this environment education is wasteful in the sense that it does not affect productivity. Nonetheless, it may improve the allocation of ex ante heterogeneous workers over jobs because it provides a signal about the innate ability of workers. This and other topics are on our agenda for future research. 


\section{References}

[1] Acemoglu, Daron (1996), "A Microfoundation for Social Increasing Returns in Human Capital Accumulation", Quarterly Journal of Economics, 111(3), 779-804.

[2] — (1997), "Training and Innovation in an Imperfect Labor Market", Review of Economic Studies, 64, 445-464.

[3] Acemoglu, Daron and Robert Shimer (1999), "Holdups and Efficiency With Search Frictions", International Economic Review, 40(4), 827-849.

[4] Burdett, Kenneth, Shouyong Shi and Randall Wright (2001), "Pricing and Matching With Frictions", Journal of Political Economy, 109(5), 1060-1085.

[5] Butters, Gerard R. (1977), "Equilibrium Distribution of Sales and Advertising Prices", Review of Economic Studies, 44, 465-491.

[6] Cole, Harold L., George J. Mailath and Andrew Postlewaith (1998), "Efficient Non-contractible Investments", Federal Reserve Bank of Minneapolis, Staff Report 253.

[7] Davis, Steven J. (2001), "The Quality Distribution of Jobs and the Structure of Wages in Search Equilibrium", NBER Working Paper, No. 8434 .

[8] Felli, Leonardo and Kevin Roberts (2000), "Does Competition Solve the Hold-up Problem?", mimeo, University of Oxford.

[9] Grout, Paul (1984), "Investment and Wages in the Absense of Binding Contracts: A Nash Bargaining Approach", American Economic Review, 86, 478-501. 
[10] Hosios, Arthur (1990), "On the Efficiency of Matching and Related Models of Search and Unemployment", Review of Economic Studies, 57, 279298.

[11] Julien, Benoit, John Kennes and Ian King (2000), "Bidding for Labor", Review of Economic Dynamics, 3(4), 619-649.

[12] — (2001), "Auctions and Posted Prices in Directed Search Equilibrium", Topics in Macroeconomics (BE Journal in Macroeconomics), 1(1), Article 1.

[13] Kultti, Klaus (1998), "Efficient Allocation of Agents and the Trading Mechanisms", Helsinki School of Economics and Business Administration, Working Paper No. W-206.

[14] — (1999), "Equivalence of Auctions and Posted Prices", Games and Economic Behavior, 27(1), 106-113.

[15] Laing, Derek, Theodore Palivos and Ping Wang (1995), "Learning, Matching and Growth", Review of Economic Studies, 62, 115-129.

[16] MacLeod, W. Bentley and James M. Malcomson (1993), "Investments, Holdup and the Form of Market Contracts", American Economic Review, 83, 811-837.

[17] Malcomson, James M. (1998), "New Developments in the Study of Contracts in Labour Markets", Chapter 3 in Orly Ashenfelter and David Card (eds.): Handbook of Labor Economics, Vol. 3b, North-Holland Publishers, Amsterdam.

[18] Masters, Adrian M. (1998), "Efficiency of Investment in Human and Physical Capital in a Model of Bilateral Search and Bargaining", International Economic Review, 39, 477-493. 
[19] McAfee, R. Preston (1993), "Mechanism Design by Competing Sellers", Econometrica, 61, 1281-1312.

[20] Moen, Espen R. (1996), "Human Capital Investments and Market Imperfections", SNF Oslo, Working Paper No. 1996-8.

[21] (1997), "Competitive Search Equilibrium", Journal of Political Economy, 105, 385-411.

[22] — (1999), "Education, Ranking and Competition for Jobs", Journal of Labor Economics, 17(4), 694-723.

[23] Mortensen, Dale T. (1982), "Property Rights and Efficiency in Mating, Racing, and Related Games", American Econimic Review, 72, 968-979.

[24] Peters, Michael (1997), "A Competitive Distribution of Auctions", Review of Economic Studies, Vol. 64, 97-123.

[25] — (2001), "Surplus Extraction and Competition", Review of Economic Studies, 68, 613-631.

[26] Pissarides, Christopher A. (1984), "Search Intensity, Job Advertising and Efficiency", Journal of Labor Economics, 2, 128-143.

[27] Riley, John G. and William F. Samuelson, "Optimal Auctions", Americam Economic Review, 71, 381-392.

[28] Shimer, Robert (1996), "Essays in Search Theory", PhD dissertation, Massachusetts Institute of Technology.

[29] (1999), "Job Auctions", mimeo, Princeton University. 


\section{Appendix}

\section{Proof of Proposition 1}

(i) Characterization of efficient stationary allocations

Consider the Lagrangian function $£$ associated with eqs. (2)-(4):

$$
\begin{aligned}
£= & \sum_{t=0}^{\infty} \beta^{t}\left\{u(t) \mu(q(t)) Y(k(t))-\frac{u(t)}{q(t)}(1-\beta(1-s)) p k(t)\right. \\
& -\lambda(t)[u(t+1)-u(t)-s(1-u(t))+(1-s) \mu(q(t)) u(t)]\}
\end{aligned}
$$

where $\lambda(t)$ is the (undiscounted) shadow value of an unemployed worker in period $t$ and $Y(k(t))$ satisfies (4). Since we are interested in steady states, we henceforth suppress all time indices. The first-order conditions for $k, q$ and $u$ can then be written succinctly as:

$$
\begin{aligned}
& u\left[\mu(q)(1-s) \beta\left[\frac{f^{\prime}(k)}{1-\beta(1-s)}-p\right]-\frac{1}{q}(1-\beta(1-s)) p\right] \leq 0, \\
& u\left[\mu^{\prime}(q) Y(k)+\frac{1}{q^{2}}(1-\beta(1-s)) p k-\lambda(1-s) \mu^{\prime}(q)\right] \leq 0, \\
& \beta^{t}\left[\mu(q) Y(k)-\frac{1}{q}(1-\beta(1-s)) p k+\lambda(1-s)(1-\mu(q))\right]-\beta^{t-1} \lambda \leq 0,
\end{aligned}
$$

At an internal solution, the above conditions will hold with equality, while the employment rate $u$ satisfies

$$
s(1-u)=(1-s) \mu(q) u .
$$

The existence of an internal maximum is demonstrated below. In this section we want to show that the solution of conditions (25)-(27) coincides with the 
solution of (5). First of all, notice that the first order conditions for $k$ and $q$ are linear in $u$. For any given value of $\lambda$, eqs. (25) and (26) can therefore be solved for the optimal choice of $k$ and $q$, independent of the value of $u$. Denote these optimal choices by $k(\lambda)$ and $q(\lambda)$. Inspection of (25) and (26) shows that these variables correspond to the solution of the following static optimization problem:

$$
\max _{\{k, q\}}\left(\mu(q) Y(k)-\lambda(1-s) \mu(q)-\frac{1}{q}(1-\beta(1-s)) p k\right)
$$

Equation (29) is a recursion that defines the shadow value of workers ${ }^{19}$; each unemployed worker is hired with probability $\mu(q)$ and with probability $(1-s)$ this match yields net-output $f(k) /(1-\beta(1-s))$ in the next period. From this we need to deduce the implicit cost of hiring labour $\lambda$ and capital $p k$. Moreover, while a worker is unemployed the planner sustains $1 / q$ vacancies for her, and the flow cost of these vacancies is given by the last term on the right.

In order to use (29) to solve for the efficient value of $k$ and $q$, we need to show that $\lambda$ is independent of $u$. This follows from eq. (27). Solving this equation for $\lambda$ yields:

$$
\lambda=\beta\left(\frac{\beta(1-s) \eta(q)\left(\frac{f(k)}{1-\beta(1-s)}-p k\right)-(1-\beta(1-s)) p k}{(1-\beta(1-s)) q+\beta(1-s) \eta(q)}\right),
$$

which shows that the shadow value of workers does not depend on $u$. The same is therefore true for $k(\lambda)$ and $q(\lambda)$. Finally, substituting (30) in (29)

\footnotetext{
${ }^{19}$ More precisely, according to (27) the maximand in (29) corresponds to the flow return $(1-\beta(1-s)) \lambda$.
} 
yields eqn. (5) in the main text. The solution to this static optimization problem thus characterizes the efficient (steady state) capital investment and queue length, while the associated unemployment rate $u^{S}$ can be found by substituting $q^{S}$ into (28).

(ii) Existence of an interior solution

Let $V(k, q)$ denote the value of maximand (5) which is continuous on $(k, q) \in$ $(0, \infty)^{2}$. The following results are immediate: $\lim _{q \rightarrow 0} V(k, q)<0 ; \lim _{q \rightarrow \infty} V(k, q)=$ $0 ; \lim _{k \rightarrow 0} V(k, q)=0 ; \lim _{k \rightarrow \infty} V(k, q)<0 ;$

Extremal values of $k$ and/or $q$ can therefore never be a solution as long as we can show that there exist positive and finite values of $k$ and $q$ for which $V(k, q)$ is strictly positive. Following Acemoglu and Shimer (1999) this can be established using the Fundamental Theorem of Calculus. Fix any positive value of $q$ such that $\eta(q)>0$ and define the value of $k^{q}$ by:

$$
\frac{\beta(1-s) \eta(q)}{1-\beta(1-s)+\beta(1-s) \eta(q)} f^{\prime}\left(k^{q}\right)=(1-\beta(1-s)) p
$$

Such a strictly positive value for $k^{q}$ always exists, since we assumed that $\lim _{k \rightarrow 0} f^{\prime}(k)=\infty$. Then by the fundamental theorem of calculus, it follows that $V\left(q, k^{q}\right)$ is equal to:

$$
\begin{aligned}
& \int_{0}^{k^{q}} \frac{(1-s) \beta \eta(q) f^{\prime}(\kappa)-(1-\beta(1-s))(1-\beta(1-s)+(1-s) \beta \eta(q)) p}{(1-\beta(1-s)) q+\beta(1-s) \eta(q)} d \kappa> \\
& \int_{0}^{k^{q}} \frac{(1-s) \beta \eta(q) f^{\prime}\left(k^{q}\right)-(1-\beta(1-s))(1-\beta(1-s)+(1-s) \beta \eta(q)) p}{(1-\beta(1-s)) q+\beta(1-s) \eta(q)} d \kappa=0
\end{aligned}
$$

which is strictly positive. The maximum is therefore an interior extremum and the Kuhn-Tucker conditions are necessary conditions. In addition, the 
payoffs in the original infinite horizon problem are simply equal to the discounted sum of the constant per period payoffs. These payoffs are therefore also well-defined and since $q^{S}$ is strictly positive and finite, the steady state unemployment rate is strictly positive. Equations (25)-(29) therefore hold with equality and a stationary solution to the original dynamic programme exists and coincides with the solution to (5) in the main text.

(iii) Properties of the efficient allocation

The first-order conditions for maximization problem (5) are specified in Corollary 2. The first-order condition for $k^{S}$ defines a strictly increasing and continuous function $K^{S}(q)$ that maps $(0, \infty)$ onto $\left(0, \bar{k}^{S}\right)$, where $\bar{k}^{S}$ is implicitly defined by

$$
\beta(1-s) \frac{f^{\prime}\left(\bar{k}^{S}\right)}{1-\beta(1-s)}=p .
$$

Similarly, first-order condition (7) defines a strictly increasing function $Q^{S}(k)$ that maps $(0, \infty)$ onto $\left(0, \widehat{k}^{S}\right)$, where $\widehat{k}^{S}$ satisfies

$$
\beta(1-s) \frac{f\left(\widehat{k}^{S}\right) / \widehat{k}^{S}}{1-\beta(1-s)}=p
$$

From the concavity of $f(k)$ it follows that $\widehat{k}^{S}>\bar{k}^{S}$. Hence, in the domain $(q, k)$ the graph of $Q^{S}$ lies above the graph associated with $K^{S}$ for values of $q$ close to infinity. Moreover, both graphs start in the origin and from (i) it follows that they intersect at least once more on the interior.

\section{Proof of Proposition 4}

\section{(i) Existence}

First, consider the graph of eqn. (15). Since the first term on the left is increasing in $q$ and $f(k)$ is strictly concave, this graph is upward sloping in $(q, k)$ space. Moreover, the left-hand side of (15) is continuously differentiable 
with respect to $q$ and $k$ on the whole domain $[0, \infty]^{2}$. The conditions of the implicit function theorem are therefore satisfied and eqn. (15) implicitly defines a function $K^{R}(q)$ that is monotonically increasing, continuous and differentiable with $K(0)=0$ and $\lim _{q \rightarrow \infty} K^{R}(q)=\bar{k}$, where $0<\bar{k}<\infty$ is implicitly defined by:

$$
\beta(1-s) \frac{f^{\prime}(\bar{k})}{1-\beta(1-s)}=p
$$

Next, dividing (17) by (15) we arrive at the following expression:

$$
\frac{\beta(1-s) e^{-q}}{1-\beta(1-s)+\beta(1-s)\left(1-e^{-q}-q e^{-q}\right)}=\frac{1-\epsilon(k)}{\epsilon(k)}
$$

The left-hand side of (34) is a strictly decreasing function of $q$ that maps $[0, \infty]$ onto $\left[0, \frac{\beta(1-s)}{1-\beta(1-s)}\right]$. Hence, whenever $\epsilon(k)>1-\beta(1-s)$, there exists a value of $q>0$ that solves (34). Let us denote this solution by $Q^{R}(k)$.

Under Condition 1, there are three possible cases. Case $I$ : The production function is iso-elastic. In this case $Q^{R}(k)$ defines a vertical line at some strictly positive and finite value of $q$. Case II: The elasticity of the production function is monotonically decreasing. In this second case, $Q^{R}(k)$ defines a downward-sloping curve. This curve starts at a vertical intercept $(q, k)=$ $(0, \widetilde{k})$, where $\widetilde{k}>0$ is implicitly defined by:

$$
\frac{1}{1-\beta(1-s)}=\frac{f(\widetilde{k})}{f^{\prime}(\widetilde{k}) \widetilde{k}}
$$

and it cuts the $x$-axis $(k=0)$ at some strictly positive value of $q$. Case III: The elasticity of the production function is locally increasing. As a result, the graph of $Q^{R}(k)$ has a positive slope. However, given that $f(k)$ is concave, 
the elasticity cannot be monotonically increasing on the entire domain. In the rest of the domain we are therefore in Cases I or II.

In all three cases, the graphs of $Q^{R}(k)$ and $K^{R}(q)$ intersect at least once on the interior of $[0, \infty]^{2}$. Each such intersection defines an equilibrium. Furthermore, if $\epsilon(k)$ is non-increasing the equilibrium is unique.

\section{Proof of Proposition 8}

Consider the Lagrangian function $\mathcal{L}^{D}$ associated with $P 1$ in Lemma 7:

$$
\mathcal{L}^{D}=\phi \frac{f(k)}{1-\beta}+\mu\left[\vartheta \frac{f(k)}{1-\beta(1-s)}-k p\right],
$$

where $\phi$ and $\vartheta$ satisfy:

$$
\begin{aligned}
\phi & =\frac{\beta(1-s) e^{-q}}{1-\beta(1-s)+\beta(1-s)\left(1-q e^{-q}\right)} \\
\vartheta & =\frac{\beta(1-s)\left(1-e^{-q}-q e^{-q}\right)}{1-\beta(1-s)+\beta(1-s)\left(1-q e^{-q}\right)},
\end{aligned}
$$

while $\mu$ denotes the Lagrangian multiplier.

Assuming an internal solution, we obtain the following first-order conditions

$$
\begin{gathered}
\phi \frac{f^{\prime}(k)}{1-\beta}+\mu\left[\vartheta \frac{f^{\prime}(k)}{1-\beta(1-s)}-p\right]=0 \\
\frac{\partial \phi}{\partial q(k)} \frac{f(k)}{1-\beta}+\mu \frac{\partial \vartheta}{\partial q(k)} \frac{f(k)}{1-\beta(1-s)}=0 \\
\vartheta \frac{f(k)}{1-\beta(1-s)}-k p=0
\end{gathered}
$$


Equation (37) defines the value of $\mu$.

$$
\mu=\frac{1-\beta(1-s)+\beta(1-s)\left(1-e^{-q}\right)}{(1-\beta(1-s)) q+\beta(1-s)\left(1-e^{-q}\right)} \frac{1-\beta(1-s)}{1-\beta}
$$

Substituting this solution into (36) yields:

$$
\frac{\beta(1-s)\left(1-e^{-q}\right)}{1-\beta(1-s)+\beta(1-s)\left(1-e^{-q}\right)}\left(\frac{f^{\prime}(k)}{1-\beta(1-s)}\right)=p
$$

This expression coincides with eq. (6). Hence, in any equilibrium with directed search the investment margin is efficient. The efficiency of free entry condition (38) was shown already in Section 4. The equilibrium allocation therefore coincides with an efficient allocation and Proposition 1 shows that such an efficient allocation $\left(q^{S}, k^{S}\right) \in(0, \infty)^{2}$ exists

\section{Proof of Proposition 9}

Let $J^{V}(k, \pi)$ denote the value of a vacant firm with capital-intensity $k$ and reservation bid $\pi$. For an arbitrary value of $q, J^{V}(k, \pi)$ satisfies:

$$
J^{V}(k, \pi)=\beta(1-s)\left(e^{-q} J^{V}(k, \pi)+q e^{-q} \pi+\left(1-e^{-q}-q e^{-q}\right)\left(S(k)-J^{U}\right)\right) .
$$

Similarly, a worker who applies at this firm obtains a payoff $J^{U}(k, \pi)$ that satisfies:

$$
J^{U}(k, \pi)=\beta\left(\left(1-e^{-q}\right) J^{U}+e^{-q}\left((1-s)(S(k)-\pi)+s J^{U}\right)\right) .
$$

The difference with before is that a single applicant now receives $S(k)-\pi$ rather than $S(k)-J^{V}(k)$. A firm can therefore reduce the extent of (ex post) 
rent-sharing by announcing a reservation bid $\pi>J^{V}(k)$. However, this gain needs to be offset against the drop in the expected number of applicants $q$.

In what follows we extend our restriction on the out-of-equilibrium beliefs to $\pi$. Hence, firms have rational expectations about the queue $q$ associated to all relevant values of $k$ and $\pi$. Moreover, as before this includes combinations of $(k, \pi)$ that are not yet offered by other firms. Given this restriction, the logic of Lemma 7 applies and any combination $(k, \pi)$ that is observed in equilibrium must maximize the welfare of a representative worker subject to the zero profit condition of firms. Using eqs. (10), (41) and (42) this delivers the following optimization problem:

$$
\max _{\{k, \pi, q\}} \frac{\beta(1-s) e^{-q}}{1-\beta(1-s)+\beta(1-s) e^{-q}}\left[\frac{f(k)-(1-\beta(1-s)) \pi}{1-\beta}\right]
$$

s.t.

$$
\frac{\beta(1-s) q e^{-q}}{1-\beta(1-s) e^{-q}} \pi+\frac{\beta(1-s)\left(1-e^{-q}-q e^{-q}\right)}{1-\beta(1-s) e^{-q}}\left[\frac{f(k)-(1-\beta) J^{U}}{1-\beta(1-s)}\right]-p k \geq 0 .
$$

Assume for a moment that the above programme has an internal solution. The first-order conditions for $\pi$ and $q$ can then be solved for the optimal reserve bid $\pi(k)$ as a function of $k$ and $q$. This yields:

$$
\pi(k)=\frac{\beta(1-s)\left(1-e^{-q}-q e^{-q}\right)}{1-\beta(1-s)+\beta(1-s)\left(1-q e^{-q}\right)}\left(\frac{f(k)}{1-\beta(1-s)}\right) .
$$

By virtue of eqn. (21) firms therefore prefer to announce their true outside option value. Next, substitute (43) into the objective function and the constraint of $(P 2)$. This yields the constrained optimization programme $(P 1)$ 
that is characterized in Lemma 5 and from Proposition 6 we know that this problem has an internal solution that coincides with an efficient allocation $\left(k^{S}, q^{S}\right) \in(0, \infty)^{2}$. In equilibrium the reserve bid of firms is therefore given by $\pi\left(k^{S}\right)=J^{V}\left(k^{S}\right)=p k^{S}$ and the resulting allocation is constrained efficient. 